\title{
Toxoplasma gondii and the immunity-related GTPase (IRG) resistance system in mice - A Review
}

\author{
Yang Oliver Zhao, Christoph Rohde, Jing Tao Lilue, Stephanie Könen-Waisman, \\ Aliaksandr Khaminets, Julia Petra Hunn, Jonathan Charles Howard/+ \\ Institute for Genetics University of Cologne, Zülpicher Strasse 47, 50674 Cologne, Germany
}

The immunity related GTPases (IRG proteins) constitute a large family of interferon-inducible proteins that mediate early resistance to Toxoplasma gondii infection in mice. At least six members of this family are required for resistance of mice to virulent $\mathrm{T}$. gondii strains. Recent results have shown that the complexity of the resistance arises from complex regulatory interactions between different family members. The mode of action against $\mathrm{T}$. gondii depends on the ability of IRG proteins to accumulate on the parasitophorous vacuole of invading tachyzoites and to induce local damage to the vacuole resulting in disruption of the vacuolar membrane. Virulent strains of $\mathrm{T}$. gondii overcome the IRG resistance system, probably by interfering with the loading of IRG proteins onto the parasitophorous vacuole membrane. It may be assumed that $\mathrm{T}$. gondii strains highly virulent for mice will be disadvantaged in the wild due to the rapid extinction of the infected host, while it is self-evident that susceptibility to virulent strains is disadvantageous to the mouse host. We consider the possibility that this double disadvantage is compensated in wild populations by segregating alleles with different resistance and susceptibility properties in the IRG system.

Key words: Irgb6 - TGTP - LRG47 - virulence - evolution

The importance of immunity-related GTPases (IRG) proteins for immunity against Toxoplasma gondii in mice emerged as a result of a series of accidents. By 1995, three members of the family (Irgd/IRG-47, Irgm1/LRG47 and Irgb6/TGTP) had already been discovered (Gilly \& Wall 1992, Carlow et al. 1995, Lafuse et al. 1995, Sorace et al. 1995), but functional work had been limited to a brief skirmish with viral resistance (Carlow et al. 1998) in homage to the mouse Mx1 protein, a GTPase, also inducible by interferon (although type 1 interferon, exclusively) and a powerful cell-autonomous resistance factor in mouse against orthomyxoviruses including influenza (Staeheli et al. 1986). None of the investigators who found these first IRG family members has worked on them for over a decade. In 1996, Irgm3 turned up as a weakly induced gene in a screen for transcriptional activation in $\mathrm{C} 127$ mouse fibroblasts by hepatocyte growth factor, by Greg Taylor in George van der Woude's lab at Frederick, Maryland (Taylor et al. 1996). Instead of ignoring this ugly duckling, Taylor took it up and made it his own. He quickly showed that the main inducer is IFN $\gamma$, mapped the locus to chromosome 11 and demonstrated a number of important biochemical and cell biological properties (Taylor et al. 1996, 1997). In 2000, Taylor published a genomic disruption of the Irgm 3 gene (Taylor et al. 2000). Still focused on the idea of a pathogen resistance gene, he enlisted local expertise to deter-

Financial support: Deutsche Forschungsgemeinschaft (SFB635, SFB670, SFB680)

+ Corresponding author: j.howard@uni-koeln.de

Received 10 October 2008

Accepted 29 October 2008 mine the pathogens to be tested. Ebola virus and cytomegalovirus, Listeria monocytogenes and $T$. gondii were the first candidates, producing three negatives and one spectacular positive: all the knock-out mice died within 12 days of i.p. infection with 20 brain cysts of the avirulent type II $T$. gondii strain, ME49. Why was $T$. gondii chosen in this first screen? Because Howard Young, who was working at Frederick, was friend and colleague of Alan Sher, the eminent $T$. gondii immunologist who was close by at the National Institutes of Health, and suggested that $T$. gondii might be a good system to start on the search for pathogen resistance ( $G$ Taylor, personal communication). So Irgm3 fell into the right hands at the right place. As we now know from Taylor's subsequent work, had he discovered Irgd he would have had a very weak (though measurable) Toxoplasma phenotype in the knockout (Collazo et al. 2001, unpublished), Irga6 knock-out has no phenotype by the i.p. infection with ME49 tachyzoites, though a significant phenotype by infection with bradyzoites per orem (Zerrahn \& Liesenfeld, personal communication), while Irgb6 has an expressed duplicated copy with the identical amino acid sequence (unpublished observations and Bekpen et al. 2005) and perhaps for that reason a knock-out, made well before Greg Taylor's Irgm3 knock-out by H-S Teh and colleagues at the University of British Columbia, had no striking phenotype and remains unpublished to this day (D Carlow, personal communication).

\section{IRG proteins}

Since Taylor's pioneering work forced them on our attention we have learned a great deal about the IRG proteins and in particular about their arguably privileged relationship with $T$. gondii infection. In this brief review of their properties I will finish by considering evidence 
that IRG proteins may represent a significant selective pressure on $T$. gondii infection in the wild, while $T$. gondii is also putting selective pressure on IRG genes in its intermediate hosts.

IRG proteins are induced by interferons, especially IFN $\gamma$, in all cell types so far examined (reviewed in Martens \& Howard 2006, Taylor 2007), reaching significant levels some hours after induction, thus their function can be exercised in ordinary tissue cells unconnected with the classical or innate immune systems. There is strong evidence that their function is cell-autonomous, meaning that it is exercised by IRG proteins directly in individual infected cells (Halonen et al. 2001, Martens et al. 2005). In IFN $\gamma$-treated mouse cells, $T$. gondii replication is inhibited as judged by direct inspection and by uracil incorporation assays (Remington \& Merigan 1968, Könen-Waisman \& Howard 2007) and this inhibition is already apparent as early as the first replication cycle after infection. IFN $\gamma$-dependent restriction of $T$. gondii replication is strongly blocked in cells transfected with plasmids encoding IRG proteins with mutations in the nucleotide binding site that function as dominant negatives (Martens et al. 2005 and unpublished observations).

The typical IRG protein unit is about 420 amino acids long and encoded on a single exon (Bekpen et al. 2005). Only a single crystal structure is known, that of Irga6, which shows a Ras-like GTP-binding domain suspended between $\mathrm{N}$-terminal and $\mathrm{C}$-terminal helical domains, and protein alignments of family members suggest that this general structure is valid for all (Ghosh et al. 2004). In the C57BL/6 genome there are 25 exons encoding IRG protein domains of this type (Bekpen et al. 2005 and unpublished observations). Of these, three (possibly four) adjacent pairs on Chromosome 11 (Irgb2+Irgb1, Irgb5+Irgb4, Irgb9+Irgb8 and probably also Irgb5*+Irgb3) are transcribed as long mRNAs encoding tandem IRG proteins each with two typical IRG domains (Bekpen et al. 2005 and unpublished observations). Although inducible by interferons, no work has yet been reported on these three or four proteins. Of the remaining 19 IRG-encoding exons, eight are on chromosome 18 (Irga1-Irga8) of which four (Irga1, Irga2, Irga5 and Irga8) are certainly or probably functionally pseudogenes. Irga3, Irga4, Irga6 and Irga7 appear to be normal genes encoding interferon-inducible functional units. Of these, only Irga6 has been studied in any detail. On chromosome 11, Irgb7 is presumably a pseudogene, while Irgb6 (two indistinguishable copies), Irgb10, Irgd, Irgm1, Irgm 2 and Irgm 3 have all been analyzed extensively in different pathogen-related and cell-biological contexts. An isolated IRG gene on mouse chromosome 7, Irgc, is expressed exclusively in testis and is not at present implicated in parasite resistance (Bekpen et al. 2005 and unpublished observations).

\section{Interactions with T. gondii: cell biology}

When an interferon-stimulated cell is infected by T. gondii, IRG proteins begin to accumulate on the membrane of the parasitophorous vacuole (Butcher et al. 2005, Martens et al. 2005 and unpublished observations). At least seven different IRG proteins have been shown to accumulate on the parasitophorous vacuole membrane (PVM) (Martens et al. 2005 and unpublished observations). In the intensively studied case of Irga6 it was shown recently that the accumulation on the vacuole is associated with the exchange of GDP for GTP (Hunn et al. 2008, Papic et al. 2008). Thus Irga6 on the PVM is in the active GTP-bound state. It has been repeatedly pointed out that IRG proteins have characteristics, though not sequence, in common with the dynamins (Praefcke \& McMahon 2004, Martens \& Howard 2006), large GTPases responsible for a variety of membrane modeling activities. It is therefore of interest that the PVM of T. gondii infecting an interferon-induced mouse cell becomes ruffled, vesiculated and finally disrupted resulting in release of the parasite into the cytosol (Martens et al. 2005, Ling et al. 2006, Melzer et al. 2008). A dynamin-like activity of the IRG proteins associated with the PVM could be responsible for these membrane deformation phenomena, presumably occurring, as with the dynamins, through the hydrolysis of bound GTP, although this has not yet been formally demonstrated. Once released into the cytosol, the parasite rapidly becomes moribund, for unknown reasons. It is clear that this sequence of events is dependent on the presence of IRG proteins since the whole process is greatly attenuated in cells from IRG knock-out mice (Butcher et al. 2005) and cells expressing dominant negative IRG mutants (Martens et al. 2005 and unpublished observations). Nevertheless it remains completely unknown what the IRG proteins are really doing and why so many are required on the PVM.

It has been claimed that the destruction of $T$. gondii in interferon-stimulated cells is accompanied by the inclusion of the parasite into autophagosomes (Ling et al. 2006). This conclusion is at variance with earlier evidence that, while membranes expressing the autophagic marker, LC3, are sometimes found near to or even associated with disrupted vacuoles, there is no necessary relationship between these structures (Martens et al. 2005). Furthermore, no consistent association of lysosomal membranes with disrupted vacuoles has been seen (Martens et al. 2005) again contrary to the observations of Ling et al. (2006) and arguing against the delivery of autophagosome-enclosed parasites to secondary lysosomes. Nevertheless it appears that the autophagic pathway is indeed involved in some way in the IRG resistance mechanism. We reported that IFN $\gamma$-stimulated fibroblasts from mice deficient in the autophagic regulator, atg5, were also deficient in their ability to control $T$. gondii replication (Könen-Waisman \& Howard 2007) and it has recently been shown that the accumulation of Irga6 at the PVM is attenuated in these cells (HW Virgin, personal communication and unpublished observations). In the absence of conclusive evidence for autophagy itself as a component of the IRG mechanism, these results may rather implicate other functions of atg5 associated with cell death control and replication that have surfaced recently (Luo \& Rubinsztein 2007, Pua et al. 2007).

One of the big surprises, given the large number of IRG-encoding, interferon-inducible genes, is the nonredundancy of multiple IRG proteins in resistance to $T$. 
gondii. All four genes that have been experimentally disrupted, namely Irgm1, Irgm3, Irga6 and Irgd have stronger or weaker but highly significant loss of resistance phenotypes for avirulent type II $T$. gondii strains. This may reflect the existence of multiple independent pathways of attack by IRG proteins on the parasite, but the alternative, that IRG proteins function in a coordinated manner, has recently been supported by evidence that one subset of IRG proteins function as essential regulators of the others (Hunn et al. 2008). The regulators are recognizable by an unfamiliar substitution in the otherwise highly conserved G1 motif (P-loop) in the nucleotide binding site, where a methionine replaces a conserved lysine, creating the motif GMS in place of GKS (Boehm et al. 1998). The three IRGM or "GMS" proteins of the mouse are essential for the biological function of the majority "GKS" proteins, their role apparently being to maintain the GDP-bound form of the GKS proteins until infection. In the absence of GMS proteins, GKS proteins bind GTP prematurely, precipitate as aggregates in the cytoplasm and fail to accumulate on the parasitophorous vacuole or do so in reduced amounts. In addition to this level of cooperativity there is also cooperation between GKS proteins that favours their accumulation on the parasitophorous vacuole membrane (Hunn et al. 2008).

\section{Phylogenetic considerations}

The phylogeny of IRG proteins has been the subject of one major study, which revealed the unexpected fact that IRG genes with the immune properties described above are missing from the human genome (Bekpen et al. 2005). The human genome contains a single full length IRG gene which is plainly orthologous to Irgc of mouse, the isolated IRG gene on mouse chromosome 7 that is expressed exclusively in the testis (Bekpen et al. 2005). Human IRGC is also expressed only in testis (unpublished observations). There is at present no evidence that IRGC genes, which are highly conserved in the mammals, play any role in immunity, although of course absence of evidence is not evidence of absence. It is certain that there are no IFNg- or other cytokine-inducible promoter elements in IRGC genes and expression of Irgc in the mouse is not elevated by systemic infection with L. monocytogenes, which elevates the expression of all immune IRG genes (Bekpen et al. 2005). Phylogenetically, IRGC genes are of interest but they do not help to explain the loss of immune IRG genes in the primate lineage. The human genome also contains a short open reading frame, IRGM, corresponding to the GMS family of regulatory IRG proteins in the mouse (Bekpen et al. 2005). This fragment is expressed under the control of a retroviral long terminal repeats and is expressed in five differentially-spliced isoforms differing by short tracts at the $\mathrm{C}$-terminus. The putative protein product of human IRGM is truncated at both $\mathrm{N}$ and C-termini and consists of less than 200 amino acids (varying at the $\mathrm{C}$-terminus according to isoform). It includes most of the G-domain but lacks the last beta-strand carrying the G5 motif which interacts with the base and stabilizes nucleotide binding. Despite its unpromising structure, human IRGM has been implicated experimentally in the stimulation of autophagy-related phenomena associated with both Mycobacterial and Salmonella infections and indirectly by genetic association with Crohn's disease (Singh et al. 2006, Massey \& Parkes 2007, McCarroll et al. 2008). How these effects relate to the properties of IFN $\gamma$-inducible full-length immune IRG proteins is not clear for the time being.

IRG genes have a history as old as the euchordates but no older (Bekpen et al. 2005). They are well-represented in certain fish, represented in Xenopus (Amphibia) and Anolis lizard (Reptilia), apparently completely absent from the chicken and present in most orders of mammals, including insectivores, bats, rodents, ungulates and carnivores, marsupials and monotremes. However no IRG gene except IRGC and a closely linked relative, IRGClike, also testis-expressed (unpublished observations) has yet been recovered from any Felid, including, of course, the domestic cat. The absence of immune IRG genes may be an artefact of an incomplete genome sequence. Nevertheless, if two single copy IRG genes have been recovered from the genome the absence of recovered immune IRG genes, certainly hints that these do not constitute a large family in this taxonomic group. In this respect, Felidae are clearly different from the dog, which has a large representation of immune IRG genes, at least some of which are inducible by dog IFN $\gamma$ (Bekpen et al. 2005).

\section{IRG proteins and virulence of $T$. gondii}

$T$. gondii virulence in mice is a conspicuous property of certain $T$. gondii strains. In its most extreme form virulence is seen as lethality for mice following inoculation of a single organism, for example, of a type I strain such as RH. By analysis of meiotic products from crosses between $T$. gondii of different genotypes several genetic loci encoding rhoptry kinases have recently been associated with virulence traits (Saeij et al. 2006, Taylor et al. 2006). It would, however, be unsafe to conclude that one of these gene products is responsible for resistance to the IRG mechanism since further virulence-associated loci are likely to emerge as further diversity is analyzed. Typically, virulence-associated loci show high levels of genetic divergence between alleles compared with the remarkable sequence identity in housekeeping genes and introns typical between strains of the predominant North American and European isolates, types I, II and III (Boyle et al. 2006).

There are no published experiments on the cell biology of IRG-protein-mediated $T$. gondii resistance following infection with virulent type I strains. Indeed there are no published experiments that directly compare IFN $\gamma$-induced cell-autonomous resistance to virulent and avirulent strains in vitro. We have examined this issue using the uptake of ${ }^{3} \mathrm{H}$-uracil to monitor parasite replication at three days after infection (the "Pfefferkorn assay", (Pfefferkorn \& Guyre 1984)) of C57BL/6 mouse embryonic fibroblasts (Fig. 1). We conclude that type I strains of $T$. gondii are remarkably resistant to IRG-mediated restriction since their replication in IFN $\gamma$-induced fibroblasts is barely inhibited compared with the complete inhibition of type II strains. An important but perhaps not the only component contributing to loss of IRG- 

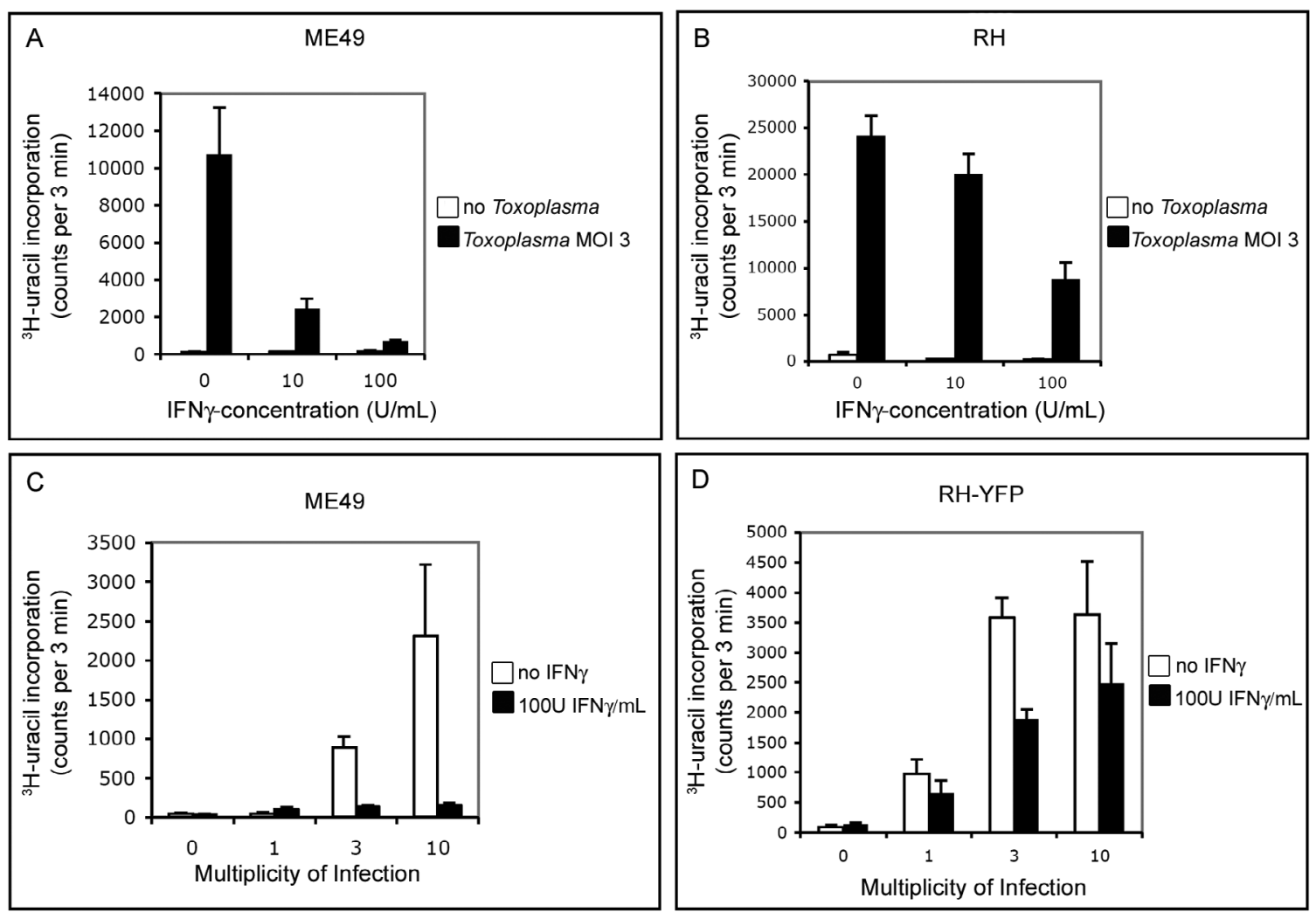

Fig. 1: the virulent RH strain is resistant to IFN $\gamma$-mediated restriction in mouse embryonic fibroblasts. Primary mouse embryonic fibroblasts of C57BL/6 strain origin were induced with mouse IFN $\gamma$ or left uninduced. After $24 \mathrm{~h}$, cells were infected with avirulent (ME49) or virulent (RH or RH-YFP) strains of Toxoplasma gondii. After a further $48 \mathrm{~h}$ culture, $3 \mathrm{H}$-uracil was added to all wells at $72 \mathrm{~h}$ cultures were harvested an assayed for incorporated counts. In A and B, proliferation of ME49 and RH was compared following treatment with different IFN $\gamma$ concentrations at a constant multiplicity of infection of 3. In a second experiment shown in C and D, proliferation of ME49 and RH-YFP was compared at different multiplicities of infection, at a constant IFN $\gamma$ concentration of $100 \mathrm{U} / \mathrm{mL}$. In both sets of conditions it is clear that RH and RH-YFP strains are markedly more resistant to the IFN $\gamma$ restriction than the ME49 strain.

mediated resistance to type I strains is a striking failure of certain IRG proteins to accumulate on the PVM (Fig. 2 and unpublished observations) leading to lack of vacuolar disruption and no release of the parasites into the cytosol (unpublished observations).

The virulence of type I strains in mice is not unique to this rather homogeneous clade. Many variant strains isolated recently in South America are also proving to be highly virulent in the mouse assay (Pena et al. 2008). We can therefore be confident that virulence for mice is a recurrent feature of recent Toxoplasma evolution. More work is required to establish the basis for virulence in each case. Thus it seems highly likely that defeat of the IRG resistance mechanism is a key determinant of virulence in type I strains, while virulence of other strains may be related to aspects of invasion or dissemination in the body that may not directly reflect the action of cell-autonomous resistance mechanisms (McLeod et al. 1989, Blackwell et al. 1993, Liesenfeld et al. 1996). Nevertheless the phenomenon of virulence, whatever its cause, shows that there is polymorphism in wild $T$. gondii for a character which has large consequences for an infected mouse, which either dies within 10 days, following a virulent infection, or survives, in the case of an avirulent infection, until it dies of other causes, for example, being eaten by a cat (Dubey et al. 1970).

A striking feature of the virulence phenomenon that has not been adequately stressed is its sporadic occurrence among intermediate hosts. Virulent strains defined by their ability to kill a mouse are shown not to be virulent even in the closely-related rat (Dubey \& Frenkel 1998, Cavailles et al. 2006). No strain of rat has yet been shown to be susceptible to any $T$. gondii strain and indeed the inbred Lewis rat strain is genetically hyper resistant and generates a sterile immunity (Cavailles et al. 2006). Nothing is known of the virulence of $T$. gondii in even more closely-related murine rodent species, but there are reports that certain American wild cricetid mice of the genus Peromyscus, which are rather distantly related to rats and mice, may also be vulnerable to $T$. gondii infection, as is the South American cricetid, Callomys callosus (Favoreto-Junior et al. 1998). Furthermore type II strains which are avirulent in mouse are proving to be virulent in California sea otters (Conrad et al. 2005, ME Grigg, personal communication) and recently atypical strains have emerged in French Guiana which are highly virulent for humans (Demar et al. 2007). Thus virulence is a character that depends both on the genotype of the 


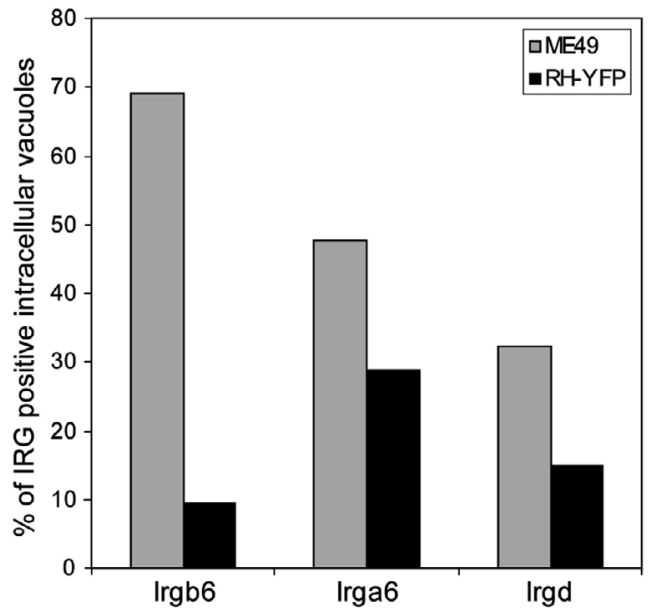

Fig. 2: IRG proteins do not accumulate normally on the PVM of virulent type I Toxoplasma gondii strains. Swiss albino-derived gs3T3 fibroblasts were induced with $200 \mathrm{U}$ IFN $\gamma / \mathrm{mL}$ for $24 \mathrm{~h}$ before infection at MOI 6 with virulent RH-YFP or avirulent ME49 strain T. gondii tachyzoites. Two hours after infection, slides were prepared for immunofluorescent staining with antibody reagents specific for Irga6, Irgb6 and Irgd. Vacuoles were scored as positive or negative for the three IRG proteins independently. The frequency of Irgb6-positive RH vacuoles was drastically reduced relative to ME49, while the frequencies of Irga6 and Irgd positive RH vacuoles were also reduced though less strikingly so. However the intensity of accumulation of Irga 6 and Irgd on the PVM, estimated by pixel counting, was reduced by about $80 \%$ on RH vacuoles relative to ME49 vacuoles (not shown). Thus all three IRG proteins are markedly defective in their ability to accumulate on the PVM of the virulent strain.

host and on the genotype of the pathogen. Unfortunately, while much is now known about virulence of type I strains for mice in terms of parasite genomic variation, little is known about the causes of resistance and susceptibility in the mouse host. In view of the critical role of the IRG system in early resistance to $T$. gondii in mice, an obvious question is whether IRG genes show significant polymorphism between mice, and whether this polymorphism interacts with polymorphism in virulence determinants in the parasite. In a preliminary analysis, we have been able to show significant coding variation in IRG genes from wild mice (unpublished observations). The impact of these variations on $T$. gondii resistance is under study.

\section{Coadaptation of host and parasite}

How important is the domestic mouse as an intermediate host in determining the evolution of $T$. gondii? It is clear that in populated areas, especially those involved in agricultural practice, mice constitute by a large margin the most abundant intermediate host, but there is explicit evidence for extensive $T$. gondii infection in many other small wild mammals that are prey for domestic cats (Afonso et al. 2007). In favour of the view that the mouse is subject to significant selective impact from $T$. gondii, it should also be noted that the mouse also suffers from two weaknesses following infection that appear to be as- sociated with the adaptive strategy of $T$. gondii, namely the selective modification of its olfactory abreaction to cat urine in favour of a positive tendency to favour this smell (Vyas et al. 2007), thus increasing the accessibility of infected mice to capture by cats; and the ability to transmit $T$. gondii vertically without significant injury to the progeny (Owen \& Trees 1998), enabling persistence of the parasite in a mouse lineage or deme despite the short average lifetime of individual mice. Behavioral modification possibly favouring capture by cats has also been observed in T. gondii-infected Rattus norvegicus (Berdoy et al. 2000), while non-pathogenic vertical transmission of $T$. gondii has also been documented in the wild European field mouse, Apodemus sylvaticus, another common prey to cats (Owen \& Trees 1998). It appears, therefore, that several small potential prey species are subject to significant selective pressure from $T$. gondii infection, but enumeration of the relative importance of individual species for the local, regional and global circulation of $T$. gondii is a challenge for the future.

The existence of virulence, leading to an early death of the host without bradyzoite conversion and encystment looks like an adaptive error by both Toxoplasma and host. What is the explanation for this anomaly? The most plausible explanation is that virulence results from a failure of coadaptation between pathogen and host. Why should this arise? There appear to be two kinds of evolutionary explanation. In one case, one can argue that the $T$. gondii genotype that is virulent for mice is coadapted for avirulence in a different, evolutionarily significant, intermediate host species, perhaps one from a divergent taxonomic group such as a small insectivore (mole or shrew). In the second case, the T. gondii that is virulent for a specific mouse strain in a laboratory test may be coadapted for avirulence in a mouse of a different resistance genotype. While it seems clear that the selective optimum for the host is to achieve sterile immunity following infection with $T$. gondii, this optimal state appears to be difficult to reach: so far only the Lewis strain rat has been found to be genetically endowed with this capability (Cavailles et al. 2006). The nature of this resistance, due to a dominant allele at the Toxo-1 locus on rat chromosome 10 near to, but apparently not identical to, a group of IRG loci, is under investigation (Cavailles et al. 2006). However, while hyper resistance may be advantageous for the host, it is equally clear that it is disadvantageous for the parasite, and the rarity with which hyper resistance has been achieved presumably indicates that $T$. gondii has access to rapid evasion strategies. It is another challenge for the future to understand the mechanism and the dynamics of these complex evolutionary processes. For the moment, our own research is devoted to establishing the role of the IRG genes in these processes. While a widespread analysis of genetic polymorphism and resistance to T. gondii in an ecological context can hardly fail to be interesting, it is important to realize that IRG-mediated resistance is not directed exclusively at $T$. gondii, and indeed a polymorphism in the expression level of an IRG gene has already been shown to contribute to variation in resistance to a human-derived Chlamydia trachomatis strain (Bernstein-Hanley 
et al. 2006), but not to the mouse-specific Chlamydia muridarum (Coers et al. 2008). Whether IRG genes contribute to resistance in mice to any other adapted pathogen except $T$. gondii still remains to be determined.

\section{ACKNOWLEDGEMENTS}

To Dr. Douglas Carlow and Dr. Greg Taylor, for some historical information about the early days of the IRG story, to Jens Zerrahn and Oliver Liesenfeld, for information on the Toxoplasma susceptibility phenotype of their Irga6 knock-out, to many participants at the Toxo100 Conference at Búzios, for the exchange of information relevant to this topic, and for all past and present members of our laboratory to these studies.

\section{REFERENCES}

Afonso E, Poulle ML, Lemoine M, Villena I, Aubert D, Gilot-Fromont E 2007. Prevalence of Toxoplasma gondii in small mammals from the Ardennes region, France. Folia Parasitol (Praha) 54: 313-314.

Bekpen C, Hunn JP, Rohde C, Parvanova I, Guethlein L, Dunn DM, Glowalla E, Leptin M, Howard JC 2005. The interferon-inducible p47 (IRG) GTPases in vertebrates: loss of the cell autonomous resistance mechanism in the human lineage. Genome Biol 6: R92.

Berdoy M, Webster JP, Macdonald DW 2000. Fatal attraction in rats infected with Toxoplasma gondii. Proc Biol Sci 267: 1591-1594.

Bernstein-Hanley I, Coers J, Balsara ZR, Taylor GA, Starnbach MN, Dietrich WF 2006. The p47 GTPases Igtp and Irgb10 map to the Chlamydia trachomatis susceptibility locus Ctrq-3 and mediate cellular resistance in mice. Proc Natl Acad Sci USA 103: 14092-14097.

Blackwell JM, Roberts CW, Alexander J 1993. Influence of genes within the MHC on mortality and brain cyst development in mice infected with Toxoplasma gondii: kinetics of immune regulation in BALB H-2 congenic mice. Parasite Immunol 15: 317-324.

Boehm U, Guethlein L, Klamp T, Ozbek K, Schaub A, Fütterer A, Pfeffer K, Howard JC 1998. Two families of GTPases dominate the complex cellular response to interferon-g. J Immunol 161: 6715-6723.

Boyle JP, Rajasekar B, Saeij JP, Ajioka JW, Berriman M, Paulsen I, Roos DS, Sibley LD, White MW, Boothroyd JC 2006. Just one cross appears capable of dramatically altering the population biology of a eukaryotic pathogen like Toxoplasma gondii. Proc Natl Acad Sci USA 103: 10514-10519.

Butcher BA, Greene RI, Henry SC, Annecharico KL, Weinberg JB, Denkers EY, Sher A, Taylor GA 2005. p47 GTPases Regulate Toxoplasma gondii Survival in Activated Macrophages. Infect Immun 73: 3278-86.

Carlow D, Marth J, Clark-Lewis I, Teh H-S 1995. Isolation of a gene encoding a developmentally regulated $\mathrm{T}$ cell specific protein with a guanine nucleotide triphosphate-binding motif. J Immunol 154: 1724.

Carlow DA, Teh S-J, Teh H-S 1998. Specific antiviral activity demonstrated by TGTP, a member of a new family of interferon-induced GTPases. J Immunol 161: 2348-2355.

Cavailles P, Sergent V, Bisanz C, Papapietro O, Colacios C, Mas M, Subra JF, Lagrange D, Calise M, Appolinaire S, Faraut T, Druet P, Saoudi A, Bessieres MH, Pipy B, Cesbron-Delauw MF, Fournie GJ 2006. The rat Toxol locus directs toxoplasmosis outcome and controls parasite proliferation and spreading by macrophagedependent mechanisms. Proc Natl Acad Sci USA 103: 744-749.

Coers J, Bernstein-Hanley I, Grotsky D, Parvanova I, Howard JC, Taylor GA, Dietrich WF, Starnbach MN 2008. Chlamydia mu- ridarum evades growth restriction by the IFN-gamma-inducible host resistance factor Irgb10. J Immunol 180: 6237-6245.

Collazo CM, Yap GS, Sempowski GD, Lusby KC, Tessarollo L, Woude GF, Sher A, Taylor GA 2001. Inactivation of LRG-47 and IRG-47 reveals a family of interferon gamma-inducible genes with essential, pathogen-specific roles in resistance to infection. $J$ Exp Med 194: $181-188$.

Conrad PA, Miller MA, Kreuder C, James ER, Mazet J, Dabritz H, Jessup DA, Gulland F, Grigg ME 2005. Transmission of Toxoplasma: clues from the study of sea otters as sentinels of Toxoplasma gondii flow into the marine environment. Int J Parasitol 35: $1155-1168$.

Demar M, Ajzenberg D, Maubon D, Djossou F, Panchoe D, Punwasi W, Valery N, Peneau C, Daigre JL, Aznar C, Cottrelle B, Terzan L, Darde ML, Carme B 2007. Fatal outbreak of human toxoplasmosis along the Maroni River: epidemiological, clinical and parasitological aspects. Clin Infect Dis 45: e88-95.

Dubey JP, Frenkel JK 1998. Toxoplasmosis of rats: a review, with considerations of their value as an animal model and their possible role in epidemiology. Vet Parasitol 77: 1-32.

Dubey JP, Miller NL, Frenkel JK 1970. The Toxoplasma gondii oocyst from cat feces. J Exp Med 132: 636-662.

Favoreto-Junior S, Ferro EA, Clemente D, Silva DA, Mineo JR 1998. Experimental infection of Calomys callosus (Rodentia: Cricetidae) by Toxoplasma gondii. Mem Inst Oswaldo Cruz 93: 103-107.

Ghosh A, Uthaiah R, Howard J, Herrmann C, Wolf E 2004. Crystal structure of IIGP1: a paradigm for interferon-inducible p47 resistance GTPases. Mol Cell 15: 727-739.

Gilly M, Wall R 1992. The IRG-47 gene is IFN-gamma induced in B cells and encodes a protein with GTP-binding motifs. J Immunol 148: 3275-3281.

Halonen SK, Taylor GA, Weiss LM 2001. Gamma interferon-induced inhibition of Toxoplasma gondii in astrocytes is mediated by IGTP. Infect Immun 69: 5573-5576.

Hunn JP, Koenen-Waisman S, Papic N, Schroeder N, Pawlowski N, Lange R, Kaiser F, Zerrahn J, Martens S, Howard JC 2008. Regulatory interactions between IRG resistance GTPases in the cellular response to Toxoplasma gondii. Embo J 27: 2495-2509.

Könen-Waisman S, Howard JC 2007. Cell-autonomous immunity to Toxoplasma gondii in mouse and man. Microbes Infect 9: 1652-1661.

Lafuse WP, Brown D, Castle LM, Zwilling BS 1995. Cloning and characterization of a novel cDNA that is IFN-gamma-induced in mouse peritoneal macrophages and encodes a putative GTPbinding protein. J Leukoc Biol 57: 477-483.

Liesenfeld O, Kosek J, Remington JS, Suzuki Y 1996. Association of CD4+ T cell-dependent, interferon-gamma-mediated necrosis of the small intestine with genetic susceptibility of mice to peroral infection with Toxoplasma gondii. J Exp Med 184: 597-607.

Ling YM, Shaw MH, Ayala C, Coppens I, Taylor GA, Ferguson DJ, Yap GS 2006. Vacuolar and plasma membrane stripping and autophagic elimination of Toxoplasma gondii in primed effector macrophages. J Exp Med 203: 2063-2071.

LuoS, Rubinsztein DC 2007. Atg5 and Bcl-2 provide novel insights into the interplay between apoptosis and autophagy. Cell Death Differ 14: 1247-1250.

Martens S, Howard J 2006. The interferon-inducible GTPases. Annu Rev Cell Dev Biol 22: 559-589.

Martens S, Parvanova I, Zerrahn J, Griffiths G, Schell G, Reichman G, Howard JC 2005. Disruption of Toxoplasma gondii parasitophorous vacuoles by the mouse $\mathrm{p} 47$ resistance GTPases. PLOS Pathogens 1: e24. 
Massey DC, Parkes M 2007. Genome-wide association scanning highlights two autophagy genes, ATG16L1 and IRGM, as being significantly associated with Crohn's disease. Autophagy 3: 649-651.

McCarroll SA, Huett A, Kuballa P, Chilewski SD, Landry A, Goyette P, Zody MC, Hall JL, Brant SR, Cho JH, Duerr RH, Silverberg MS, Taylor KD, Rioux JD, Altshuler D, Daly MJ, Xavier RJ 2008. Deletion polymorphism upstream of IRGM associated with altered IRGM expression and Crohn's disease. Nat Genet 40: $1107-1112$.

McLeod R, Skamene E, Brown CR, Eisenhauer PB, Mack DG 1989. Genetic regulation of early survival and cyst number after peroral Toxoplasma gondii infection of A x B/B x A recombinant inbred and B10 congenic mice. J Immunol 143: 3031-3034.

Melzer T, Duffy A, Weiss LM, Halonen SK 2008. IGTP is necessary for Toxoplasma vacuolar disruption and induces parasite egression in IFN \{gamma\} stimulated astrocytes. Infect Immun 76: 4883-4894.

Owen MR, Trees AJ 1998. Vertical transmission of Toxoplasma gondii from chronically infected house (Mus musculus) and field (Apodemus sylvaticus) mice determined by polymerase chain reaction. Parasitology 116: 299-304.

Papic N, Hunn JP, Pawlowski N, Zerrahn J, Howard JC 2008. Inactive and active states of the interferon-inducible resistance GTPase, Irga6, in vivo. J Biol Chem 283: 32143-32151.

Pena HF, Gennari SM, Dubey JP, Su C 2008. Population structure and mouse-virulence of Toxoplasma gondii in Brazil. Int J Parasitol 38: 561-569.

Pfefferkorn ER, Guyre PM 1984. Inhibition of growth of Toxoplasma gondii in cultured fibroblasts by human recombinant gamma interferon. Infect Immun 44: 211-216.

Praefcke GJK, McMahon HT 2004. The dynamin superfamily: universal membrane tubulation and fission molecules? Nat Rev Mol Cell Biol 5: 133-147.

Pua HH, Dzhagalov I, Chuck M, Mizushima N, He YW 2007. A critical role for the autophagy gene Atg5 in T cell survival and proliferation. $J$ Exp Med 204: 25-31.

Remington JS, Merigan TC 1968. Interferon: protection of cells infected with an intracellular protozoan (Toxoplasma gondii). Science 161: 804-806.
Saeij JP, Boyle JP, Coller S, Taylor S, Sibley LD, Brooke-Powell ET, Ajioka JW, Boothroyd JC 2006. Polymorphic secreted kinases are key virulence factors in toxoplasmosis. Science 314: 1780-1783.

Singh SB, Davis AS, Taylor GA, Deretic V 2006. Human IRGM induces autophagy to eliminate intracellular mycobacteria. Science 313: 1438-1431.

Sorace JM, Johnson RJ, Howard DL, Drysdale BE 1995. Identification of an endotoxin and IFN-inducible cDNA: possible identification of a novel protein family. J Leukoc Biol 58: 477-484.

Staeheli P, Haller O, Boll W, Lindenmann J, Weissmann C 1986. Mx protein: constitutive expression in 3T3 cells transformed with cloned Mx cDNA confers selective resistance to influenza virus. Cell 44: 147-158.

Taylor G, Collazo C, Yap G, Nguyen K, Gregorio T, Taylor L, Eagleson B, Secrest L, Southon E, Reid S, Tessarollo L, Bray M, McVicar D, Komschlies K, Young H, Biron C, Sher A, Vande Woude GF 2000. Pathogen-specific loss of host resistance in mice lacking the IFN-gamma-inducible gene IGTP. PNAS 97: 751-755.

Taylor GA 2007. IRG proteins: key mediators of interferon-regulated host resistance to intracellular pathogens. Cell Microbiol 9: 1099-1107.

Taylor GA, Jeffers M, Largaespada DA, Jenkins NA, Copeland NG, Vande Woude GF 1996. Identification of a novel GTPase, the inducible expressed GTPase, that accumulates in responses to interferon G. J Biol Chem 271: 20399-20405.

Taylor GA, Stauber R, Rulong S, Hudson E, Pei V, Pavlakis GN, Resau JH, Vande Woude GF 1997. The inducibly expressed GTPase localizes to the endoplasmic reticulum, independently of GTP binding. J Biol Chem 272: 10639-10645.

Taylor S, Barragan A, Su C, Fux B, Fentress SJ, Tang K, Beatty WL, Hajj HE, Jerome M, Behnke MS, White M, Wootton JC, Sibley LD 2006. A secreted serine-threonine kinase determines virulence in the eukaryotic pathogen Toxoplasma gondii. Science 314: 1776-1780.

Vyas A, Kim SK, Giacomini N, Boothroyd JC, Sapolsky RM 2007. Behavioral changes induced by Toxoplasma infection of rodents are highly specific to aversion of cat odors. Proc Natl Acad Sci USA 104: 6442-6447. 